\title{
Optimization of Ultrasound-assisted Extraction of Phenolic Compounds from Salicornia herbacea Powder
}

\author{
Hui Jeong Kim and Jun Ho Lee ${ }^{\dagger}$ \\ Department of Food Science and Engineering, Daegu University, Gyeongbuk 712-714, Korea
}

\begin{abstract}
Salicornia herbacea is rich in natural minerals, dietary fibers, and potentially health-promoting phenolic compounds. In this paper, an experimental design was applied for the optimization of the ultrasound-assisted extraction of phenolic compounds from lyophilized Salicornia herbacea powder. The expeniments were conducted in accordance with a five-level, three-variable central composite rotatable design (CCRD), and the effects of solvent concentration, extraction time, and extraction temperature were evaluated via response surface methodology (RSM). The optimal extraction conditions were as follows: ethanol concentration, 76.80\%; extraction time, 20 min; and extraction temperature, $33.21^{\circ} \mathrm{C}$; and the solvent concentration was the most significant parameter in this process, under which the predicted total phenolic content was $49.91 \mathrm{mg}$ GAE/g sample.
\end{abstract}

Key words: Salicornia herbacea, hamcho, ultrasound extraction, phenolics, optimization, RSM

\section{INTRODUCTION}

Salicornia herbacea L. (called hamcho in Korean) is an annual succulent shrub that grows in coastal wetlands on the southern and western seashores of the Korean peninsula (1-3). Salicornia herbacea is rich in natural minerals including $\mathrm{Mg}, \mathrm{Ca}, \mathrm{Fe}$, and $\mathrm{K}$, and dietary fibers (4), and has recently become the focus of renewed interest by virtue of its beneficial health effects, which include antibacterial activity and an angiotensin-converting enzyme I (ACE) inhibition effect (5). It has been utilized as a folk medicine for the treatment of constipation, obesity, diabetes, asthma, arthritis, and cancer (6), as well as the treatment of gastroenteric disorders, hepatitis, and nephropathy (5). Salicornia herbacea has also been reported to evidence several biological and physiological effects, including antidiabetic $(7,8)$, antioxidant (2, 9-11), antithrombus (3), hypocholesterolemic (12), and antiaging $(5,13)$ effects.

Phenolic compounds are secondary metabolites detected in many plants and their health-protecting capacity is of paramount importance to both consumers and producers (14). Salicornia herbacea harbors a large quantity of phenolic compounds than are detected in persimmon leaf and arrowroot (10), and these compounds may participate in its total antioxidant activities. Several extraction studies have been conducted to evaluate the phenolic contents of wheat (15), Inga edulis leaves (16), Baccharis dracunculifolia (17), date seeds (18), green and white tea (19), and parsley (20); however, only limited information is currently available regarding the efficient extraction of phenolic compounds from Salicornia herbacea.

In this study, ultrasound-assisted extraction conditions such as ethanol concentration, extraction time, and extraction temperature were optimized via response surface methodology (RSM), employing a five-level, three-variable central composite rotatable design (CCRD), in an effort to ascertain the optimal conditions for the extraction of phenolic compounds from Salicornia herbacea.

\section{MATERIALS AND METHODS}

\section{Matenials}

Fresh Salicornia herbacea plants were purchased from Dasarang Co., Ltd. (Jeollanam-do, Korea); the plants were harvested in June, 2008 in closed salt farms in Shinan, Jeollanam-do Province, Korea and were maintained in a $4^{\circ} \mathrm{C}$ refrigerator until use. The plants were cut into small pieces (approximately $10 \mathrm{~cm}$ ) and washed with running water to remove any surface dirt. Excess surface moisture was first removed with a salad spinner (WD23-210, Myeongmoon LC Corp., Gyeonggi, Korea), after which the samples were frozen at $-45^{\circ} \mathrm{C}$ for $24 \mathrm{hr}$ in a deep freezer (VLT 1450-3-D-14, Thermo Electron Corp., Asheville, NC, USA) prior to $48 \mathrm{hr}$ of lyophilization with a freeze-dryer (PPU-1100, Tokyo Rikakikai Co., Japan) at a vacuum pressure of $8.5 \mathrm{~Pa}$. The lyophi-

${ }^{\dagger}$ Corresponding author. E-mail: leejun@daegu.ac.kr

Phone: +82-53-850-6535, Fax: +82-53-850-6539 
lized Salicornia herbacea samples were milled using an analytical mill (M20, IKA, Staufen, Germany) and sieved through to yield particle sizes of less than 250 $\mu \mathrm{m}$. The powdered samples were then placed in a desiccator containing a saturated solution of $\mathrm{LiBr}$ prior to use. All chemical and solvents used in this study were of analytical grade.

\section{Ultrasound-assisted extraction of phenolic compounds}

Ultrasound-assisted extraction was conducted in an ultrasonic cleaning bath $(4020,40 \mathrm{kHz}, 400 \mathrm{~W}$, Jinwoo Engineering Co., Ltd., Korea) with a useful volume of 20 L (internal dimensions: $527 \times 324 \times 153 \mathrm{~mm}$ ). The working frequency was fixed at $40 \mathrm{kHz} .100$ milliliters of samples containing $5 \mathrm{~g}$ of the powder were placed into $250 \mathrm{~mL}$ volumetric flasks, then sonicated for different time periods at the required temperature. After extraction, the flasks were removed from the bath and water-cooled to room temperature. The extract samples were centrifuged $\left(25^{\circ} \mathrm{C} ; 15 \mathrm{~min} ; 2000 \times \mathrm{g}\right)$ and the supernatant was filtered through Whatman No. 2 paper. The filtrate was then concentrated using a rotary vacuum evaporator (N-1000, Tokyo Rikakikai Co., Tokyo, Japan) at $40^{\circ} \mathrm{C}$. The concentrates were immediately frozen at $-45^{\circ} \mathrm{C}$ for $24 \mathrm{hr}$ in a deep freezer (VLT 1450-3-D-14, Thermo Electron Corp., Asheville, NC, USA), and then lyophilized with a freeze-dryer (PPU-1100, Tokyo Rikakikai Co., Japan) at a vacuum pressure of $8.5 \mathrm{~Pa}$ for $48 \mathrm{hr}$. The processed samples were then used to determine the total phenolic content.

\section{Expenimental design}

The Central Composite Rotatable Design (CCRD) of the experiment was set up using the Design Expert software with an experimental study variable number of $K=3$, for independent variables including ethanol concentration $\left(X_{1}\right)$, extraction time $\left(X_{2}\right)$, and extraction temperature $\left(X_{3}\right)$. The process variables to be used in CCRD for $K=3$ could be processed with the software, which indicates the variable limits and their values. The dependent variable studied was total phenolic content.

18 sample combinations were generated from the software in experimental design using the design matrix and variable combinations in experimental runs, as is shown in Tables 1 and 2.

A quadratic polynomial regression model was as-

Table 1. Process variables and their levels used in the central composite rotatable design for analysis of Salicornia herbacea extracts

\begin{tabular}{lcccccc}
\hline \multirow{2}{*}{ Independent variable } & \multirow{2}{*}{ Code } & \multicolumn{5}{c}{ Coded levels } \\
\cline { 3 - 7 } & & -1.682 & -1 & 0 & 1 & +1.682 \\
\hline Ethanol concentration $(\%)$ & $X_{1}$ & 43.18 & 50 & 60 & 70 & 76.82 \\
Extraction time (min) & $X_{2}$ & 11.59 & 15 & 20 & 25 & 28.41 \\
Extraction temperature $\left({ }^{\circ} \mathrm{C}\right)$ & $X_{3}$ & 33.18 & 40 & 50 & 60 & 66.82 \\
\hline
\end{tabular}

Table 2. Experimental design of five-level, three-variable central composite rotatable design with the observed responses

\begin{tabular}{|c|c|c|c|c|}
\hline \multirow[b]{2}{*}{ Run } & \multicolumn{3}{|c|}{ Independent variables } & \multirow{2}{*}{$\begin{array}{l}\text { Total phenolics content } \\
\left(\mathrm{mg} \text { GAE eq. } / \mathrm{g} \mathrm{Sh}^{2)}\right)\end{array}$} \\
\hline & $\begin{array}{c}x_{1} \text {, Ethanol concentration } \\
(\%)\end{array}$ & $\begin{array}{l}x_{2}, \text { Extraction time } \\
\text { (min) }\end{array}$ & $\begin{array}{c}x_{3} \text {, Extraction temperature } \\
\left({ }^{\circ} \mathrm{C}\right)\end{array}$ & \\
\hline 1 & $50(-1)$ & $15(-1)$ & $40(-1)$ & 36.73 \\
\hline 2 & $70(+1)$ & $15(-1)$ & $40(-1)$ & 45.82 \\
\hline 3 & $50(-1)$ & $25(+1)$ & $40(-1)$ & 33.09 \\
\hline 4 & $70(+1)$ & $25(+1)$ & $40(-1)$ & 44.90 \\
\hline 5 & $50(-1)$ & $15(-1)$ & $60(+1)$ & 43.70 \\
\hline 6 & $70(+1)$ & $15(-1)$ & $60(+1)$ & 42.48 \\
\hline 7 & $50(-1)$ & $25(+1)$ & $60(+1)$ & 43.09 \\
\hline 8 & $70(+1)$ & $25(+1)$ & $60(+1)$ & 45.82 \\
\hline 9 & $43.18(-1.682)$ & $20(0)$ & $50(0)$ & 33.70 \\
\hline 10 & $76.82(+1.682)$ & $20(0)$ & $50(0)$ & 50.36 \\
\hline 11 & $60(0)$ & $11.59(-1.682)$ & $50(0)$ & 43.09 \\
\hline 12 & $60(0)$ & $28.41(+1.682)$ & $50(0)$ & 41.27 \\
\hline 13 & $60(0)$ & $20(0)$ & $33.18(-1.682)$ & 40.36 \\
\hline 14 & $60(0)$ & $20(0)$ & $66.82(+1.682)$ & 47.64 \\
\hline 15 & $60(0)$ & $20(0)$ & $50(0)$ & 45.82 \\
\hline 16 & $60(0)$ & $20(0)$ & $50(0)$ & 43.70 \\
\hline 17 & $60(0)$ & $20(0)$ & $50(0)$ & 46.73 \\
\hline 18 & $60(0)$ & $20(0)$ & $50(0)$ & 44.30 \\
\hline
\end{tabular}

${ }^{1)}$ Gallic acid equivalent. ${ }^{2)}$ Salicornia herbacea powder. 
sumed for the prediction of the total phenolic content. The model proposed for the response was:

$$
Y=b_{0}+\sum_{i=1}^{3} b_{i} x_{i}+\sum_{I=1}^{3} b_{i i} x_{i}^{2}+\sum \sum_{i<j=1}^{3} b_{i j} x_{i} x_{j}
$$

in which $Y$ is the response variable, $b_{0}, b_{i}, b_{i i}, b_{i j}$ are the regression coefficients of variables for the intercept, linear, quadratic, and interaction terms, respectively, and $x_{i}$ and $x_{j}$ are the independent variables.

\section{Detemination of total phenolic content}

Total phenolic content was determined via the Folin-Ciocalteu method (21) with little modification. In a micro-centrifuge tube, $0.79 \mathrm{~mL}$ distilled water, 0.01 $\mathrm{mL}$ Salicornia herbacea extract were appropriately diluted, and $0.05 \mathrm{~mL}$ Folin-Ciocalteu reagent was added and mixed. After exactly $1 \mathrm{~min}, 0.15 \mathrm{~mL}$ of sodium carbonate $(20 \mathrm{~g} / 100 \mathrm{~mL})$ was added, and the mixture was mixed and allowed to stand at room temperature for 60 min in darkness. The absorbance was read at $750 \mathrm{~nm}$, and the total phenolic concentration was calculated from a calibration curve $\left(R^{2}=0.9972\right)$, using gallic acid as a standard $(0 \sim 100 \mathrm{mg} / \mathrm{L})$.

\section{Statistical analysis}

Statistical analysis of variance (ANOVA) and multiple regression were conducted using the Design-Expert v.7.0 software (22) to fit the equation. The results included the significance of the model and of each of its terms, the estimated model coefficients, the coefficient of determination, and the lack of fit test. The significance of the regression coefficient was assessed via a $t$-test.

\section{RESULTS AND DISCUSSION}

\section{Statistical analysis on adequacy of the model}

The independent and dependent variables were fitted to the second-order model equation and assessed for the goodness of fit. Regression analysis and ANOVA were conducted for the model, in order to determine the statistical significance and adequacy of the model. ANOVA of the effects of ethanol concentration, extraction time, and extraction temperature for total phenolics extraction as linear, quadratic, and interaction terms on the response variable are shown in Table 3. The results showed that the model was highly adequate with a satisfactory level of $R^{2}(=0.9342)$ and model significance. It has been suggested that the models with $R^{2}$ values of greater than 0.8 are indicative of a good fit (23).

The value of the $R^{2}$ suggests that only approximately $6 \%$ of the total variation is not explained by the model. Additionally, the ANOVA of the regression model shows that the model is highly significant, as is evident from the calculated $F$-value (12.61) and the extremely low probability value $(p=0.0008)$. The results of error analysis demonstrated that the lack of fit was not significant $(\mathrm{p}>0.05)$. The coefficient of variation $(\mathrm{CV})$ was $<10 \%$, thereby indicating that the models could be reproducible (24). Therefore, the model was shown to be adequate for prediction within the range of the studied variables.

\section{Regression model of response}

The values of the response (total phenolic content) obtained under the different experimental conditions are summarized in Table 2. The maximum phenolic compound content (50.36 mg GAE/g sample) was determined under the following experimental parameters: an ethanol concentration of $76.82 \%$, an extraction time of $20 \mathrm{~min}$, and an extraction temperature of $50^{\circ} \mathrm{C}$. The lowest phenolic compound content $(33.09 \mathrm{mg} \mathrm{GAE} / \mathrm{g}$ sample) was detected at an ethanol concentration of $50 \%$, an extraction time of $25 \mathrm{~min}$, and an extraction temperature of $40^{\circ} \mathrm{C}$.

Multiple regression analysis was conducted on the experimental data, and the coefficients of the model were assessed for significance via a Student's $t$-test; and the results are listed in Table 4. All the linear and quadratic coefficients were significant, except for $b_{2}$ and $b_{33}$ $(\mathrm{p}<0.05$ or 0.01 ). Among the interactions, only the ethanol concentration and extraction temperature interaction

Table 3. Analysis of variance on the independent variables as linear, quadratic, and interaction terms on the response variable

\begin{tabular}{lccccc}
\hline Source & df & Sum of squares & Mean square & $F$-value & Prob $>F$ \\
\hline Total model & 9 & 330.6382 & 36.7376 & 12.61 & $0.0008^{* * *}$ \\
Linear & 3 & 240.6399 & 80.2133 & 27.53 & $0.0001^{* * *}$ \\
Quadratic & 3 & 30.8156 & 10.2719 & 3.53 & 0.0684 \\
Crossproduct & 3 & 59.1827 & 19.7276 & 6.77 & $0.0138^{*}$ \\
Total error & 8 & 23.3052 & 2.9190 & \\
Lack-of-fit & 5 & 17.5430 & 3.5086 & 1.83 & 0.3288 \\
Pure error & 3 & 5.7622 & 1.9207 & \\
$R^{2}$ & & 0.9342 & & & \\
CV\% & 3.98 & & &
\end{tabular}

\footnotetext{
Significant at $\mathrm{p} \leq 0.001,{ }^{* *}$ Significant at $\mathrm{p} \leq 0.01,{ }^{*}$ Significant at $\mathrm{p} \leq 0.05$.
} 
Table 4. Test of significance for regression coefficients of predicted quadratic polynomial model

\begin{tabular}{lccc}
\hline Coefficient & $\begin{array}{c}\text { Coefficients } \\
\text { estimated }\end{array}$ & $t$-value & Prob $>F$ \\
\hline Intercept & -96.8364 & -2.64 & $0.0297^{*}$ \\
Linear & & & \\
$b_{1}$ & 2.7316 & 3.93 & $0.0044^{* *}$ \\
$b_{2}$ & -0.0884 & -0.07 & $0.9440^{*}$ \\
$b_{3}$ & 1.8267 & 2.81 & $0.0227^{*}$ \\
Quadratic & & & \\
$b_{11}$ & -0.0124 & -2.58 & $0.0328^{*}$ \\
$b_{22}$ & -0.0473 & -2.46 & $0.0391^{*}$ \\
$b_{33}$ & -0.0054 & -1.12 & 0.2933 \\
Crossproduct & & & \\
$b_{12}$ & 0.0167 & 1.38 & 0.2046 \\
$b_{13}$ & -0.0242 & -4.02 & $0.0039^{* *}$ \\
$b_{23}$ & -0.0182 & 1.51 & 0.1704 \\
\hline
\end{tabular}

${ }^{* *}$ Significant at $\mathrm{p} \leq 0.01,{ }^{*}$ Significant at $\mathrm{p} \leq 0.05$.

$\left(x_{1} x_{3}\right)$ were significant $(\mathrm{p}<0.01)$. Neglecting the non-significant terms, the final predictive equation obtained is as provided below:

$$
\begin{aligned}
Y= & -96.8364+2.7316 x_{1}+1.8267 x_{3}-0.0124 x_{1}^{2} \\
& -0.0473 x_{2}^{2}-0.0242 x_{1} x_{3}
\end{aligned}
$$

\section{Optimization of extraction conditions}

In order to assess the effects of the extraction conditions on the extraction of phenolic compounds from Salicornia herbacea powder, the response surfaces and the contour plots were constructed in accordance with Eq. (2). Fig. 1 shows the effects of ethanol concentration and extraction time on the content of total phenolic contents. The total phenolic content increased slowly with increases in the ethanol concentration at a fixed extraction time. The increase in extraction time at a fixed ethanol concentration resulted in a gradual increase in the total phenolic content, up to a certain limit.

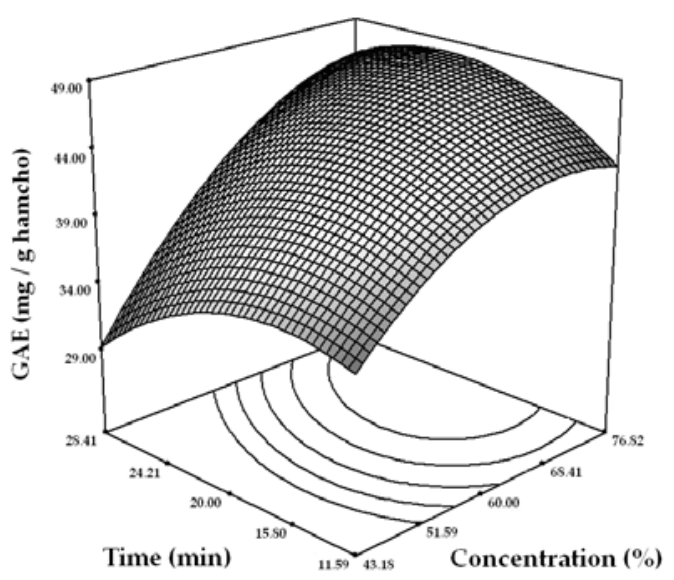

Fig. 1. Response surface for total phenolic content as a function of extraction time and ethanol concentration (extraction temperature $=50^{\circ} \mathrm{C}$ ).
The effects of ethanol concentration and extraction temperature, as shown in Fig. 2, demonstrated that the total phenolic content increased rapidly with increases in ethanol concentration at a low fixed extraction temperature, whereas an increase in extraction temperature at a low fixed ethanol concentration resulted in a considerable increase in the total phenolic content. In other words, total phenolic content evidenced a linear gain with increasing ethanol concentration and decreasing extraction temperature, thereby indicating the interaction of the ethanol concentration with the extraction temperature. A similar increase in the total phenolic content with an increase in extraction temperature was observed at a fixed extraction time, whereas a quadratic increase due to extraction time was observed, and the total phenolic content achieved its maximum value at an extraction time of approximately $19 \mathrm{~min}$ at a fixed extraction temperature (Fig. 3).

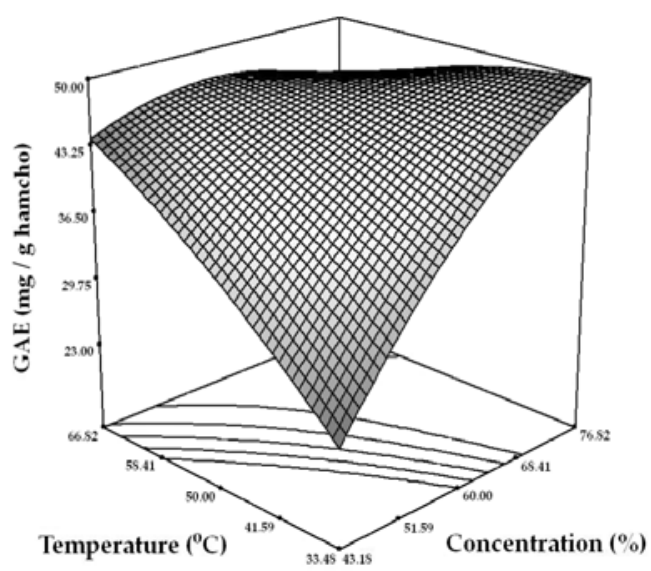

Fig. 2. Response surface for total phenolic content as a function of extraction temperature and ethanol concentration (extraction time $=20 \mathrm{~min}$ ).

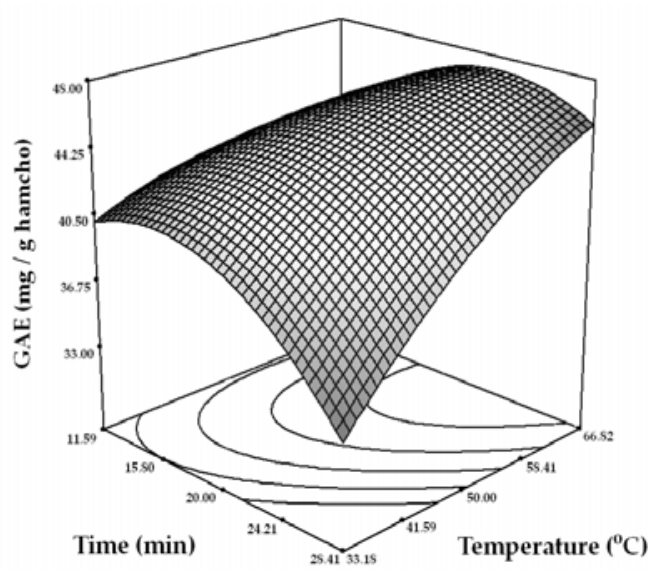

Fig. 3. Response surface for total phenolic content as a function of extraction time and extraction temperature (ethanol concentration $=60 \%$ ). 
Song et al. (10) reported that the total phenolic content of red and green Salicornia herbacea varied from 237 to $255 \mathrm{mg} / \mathrm{g}$ dry sample, using hot water and $25 \%$ ethanol extraction at $70^{\circ} \mathrm{C}$ for $24 \mathrm{hrs}$. The data are not directly comparable owing to the different extraction conditions; however, our results may indicate that the ultrasound-assisted extraction technique may markedly reduce the extraction time. The efficiency of extraction afforded by the use of ultrasound could be attributed to the fact that ultrasound waves and associated microdisturbances of cavitation bubbles near the surface of the solid resulted in the disruption of the cell walls, reductions in the particle size, and the enhancement of the mass transfer of the cell content to the solvent $(25,26)$.

Finally, the "Point Optimization" technique was utilized to optimize the level of each factor for maximum response. A maximum total phenolic content of 49.91 $\mathrm{mg}$ GAE/g sample was predicted for the following conditions: ethanol concentration, $76.80 \%$; extraction time, $20 \mathrm{~min}$; and extraction temperature, $33.21^{\circ} \mathrm{C}$.

\section{REFERENCES}

1. Kim CS, Song TG. 1983. Ecological studies on the halophyte communities at western and southern coasts in Korea. Korean J Ecol 6: 167-176.

2. Min JG, Son KT, Kim JH, Kim TJ, Park JH. 2002. Physiological and functional properties of Salicornia herbacea (Tungtungmadi) leaf extracts. Nutraceutical Food 7: 2 62-264.

3. Jang HS, Kim KR, Choi SW, Woo MH, Choi JH. 2007. Antioxidant and antithrombus activities of enzyme-treated Salicornia herbacea extracts. Ann Nutr Metab 51: 119125.

4. Min JG, Lee DS, Kim TJ, Park JH, Cho TY, Park DI. 2002. Chemical composition of Salicornia herbacea L. $J$ Food Sci Nutr 7: 105-107.

5. Lee JT, Jeong YS, An BJ. 2002. Physiological activity of Salicornia herbacea and its application for cosmetic materials. Korean J Herbol 17: 61-69.

6. Lee KY, Lee MH, Chang IY, Yoon SP, Lim DY, Jeon YJ. 2006. Macrophage activation by polysaccharide fraction isolated from Salicornia herbacea L. J Ethnopharm 103: $372-378$.

7. Lee YS, Lee S, Lee HS, Kim BK, Ohuchi K, Shin KH. 2005 . Inhibitory effects of isorhamnetin-3-O- $\beta$-D-glucoside from Salicornia herbacea on rat lens aldose reductase and sorbitol accumulation in streptozotocin-induced diabetic rat tissues. Biol Pharm Bull 28: 916-918.

8. Park SH, Ko SK, Choi JG, Chung SH. 2006. Salicornia herbacea prevents high fat diet-induced hyperglycemia and hyperlipidemia in ICR mice. Arch Pharm Res 29: 256-264.
9. Han SK, Kim SM. 2003. Antioxidative effect of Salicornia herbacea L. grown in closed sea beach. J Korean Soc Food Sci Nutr 32: 207-210.

10. Song HS, Kim DP, Jung YH, Lee MK. 2007. Antioxidant activities of red hamcho (Salicornia herbacea L.) against lipid peroxidation and the formation of radicals. Korean J Food Nutr 20: 150-157.

11. Lee WM, Sung HJ, Song JC, Cho JY, Park HJ, Kim S, Rhee MH. 2007. Effects of solvent-extracted fractions from Salicornia herbacea on anti-oxidative activity and lipopolysaccharide-induced NO production in murine macrophage RAW264.7 cells. J Exp Biomed Sci 13: 161168.

12. Cha JY, Jeon BS, Park JW, Kim BK, Jeong CY, Ryu JS, Choi CK, Cho YS. 2004. Hypocholesterolemic effect of yogurt supplemented Salicornia herbacea extracts in cholesterol-fed rats. J Life Sci 14: 747-751.

13. Lee JT, An BJ. 2002. Detection of physical activity of Salicornia herbacea. Korean J Herbol 17: 61-69.

14. Naczk M, Shahidi F. 2006. Phenolics in cereals, fruits and vegetables: Occurrence, extraction and analysis. $J$ Pharm Biom Anal 41: 1523-1542.

15. Liyana-Pathirana C, Shahidi F. 2005. Optimization of extraction of phenolic compounds from wheat using response surface methodology. Food Chem 93: 47-56.

16. Silva EM, Rogez H, Larondelle Y. 2007. Optimization of extraction of phenolics from Inga edulis leaves using response surface methodology. Sep Purif Technol 55: 381-387.

17. Piantino CR, Aquino FWB. 2008. Supercritical $\mathrm{CO}_{2}$ extraction of phenolic compounds from Baccharis dracunculifolia. J Supercritical Fluids 47: 209-214.

18. Al-Farsi MA, Lee CY. 2008. Optimization of phenolics and dietary fibre extraction from date seeds. Food Chem 108: 977-985.

19. Rusak G, Komes D, Likić S, Horžić, Kovač M. 2008. Phenolic content and antioxidant capacity of green and white tea extracts depending on extraction conditions and the solvent used. Food Chem 110: 852-858.

20. Luthria DL. 2008. Influence of experimental conditions on the extraction of phenolic compounds from parsley (Petroselinum crispum) flakes using a pressurized liquid extractor. Food Chem 107: 745-752.

21. Waterman PG, Mole S. 1994. Analysis of phenolic plant metabolites. Blackwell Scientific Publ., Oxford. p 83-91.

22. StatEase Inc. 2006. Design-Expert v.7. Minneapolis, MN, USA.

23. Joglekar AM, May AT. 1987. Product excellence through design of experiments. Cereal Food World 32: 857-868.

24. Montgomery DC. 1984. Design and analysis of experiments. 2nd ed. John Wiley and Sons, New York, NY, USA.

25. Penn R, Yeager E, Hovorka F. 1959. Effect of ultrasonic waves on concentration gradients. J Acoust Soc Am 10 : 1372-1376.

26. Paniwnyk L, Beaufoy E, Lorimer JP, Mason TJ. 2001. The extraction of rutin from flower buds on Sophora japonica. Ultrasonics Sonochem 8: 299-301.

(Received February 2, 2009; Accepted May 6, 2009) 